\title{
Collaborative Learning in Online Study Groups: An Evolutionary Game Theory Perspective
}

\author{
Raymond Chiong \\ Faculty of Higher Education, \\ Swinburne University of \\ Technology, \\ Lilydale, Victoria, Australia
}

rchiong@swin.edu.au

\author{
Jelena Jovanovic \\ Faculty of Organizational \\ Sciences, \\ University of Belgrade, \\ Belgrade, Serbia
}

jeljov@gmail.com

\section{Executive Summary}

Educational benefits of online collaborative group work have been confirmed in numerous research studies. Most frequently cited advantages include the development of skills of critical thinking and problem solving as well as skills of self-reflection and co-construction of knowledge and meaning. However, the establishment and maintenance of active collaboration in online study groups is a challenging task, primarily due to students' inability (e.g., owing to time constraints or lack of collaboration skills) or reluctance (e.g., due to the lack of or low participation of other group members) to participate actively in the group work. Aiming to better understand and contribute to the resolution of the problems of effective online group work, we followed a novel approach based on Evolutionary Game Theory (EGT). While EGT has been used extensively as a framework for studying the emergence and maintenance of cooperation in many disciplines, to the best of our knowledge, it has not yet been applied to understanding and facilitating group collaboration in online learning settings. In this paper, we present a study we have conducted in order to investigate whether, and to what extent, EGT can be applied to explain students' participation in collaborative study groups.

Keywords: collaborative learning, online group work, evolutionary game theory

\section{Introduction}

Collaborative learning in online study groups is increasingly becoming an instructional approach of choice for online courses. The benefits of collaboration in learning have been established by socially-oriented learning theories, primarily Social Constructivism (Vygotsky, 1978) and Connectivism (Siemens, 2005). Likewise, researchers have demonstrated that learning tends to be the most effective when students are in the position to work collaboratively, express their thoughts,

Material published as part of this publication, either on-line or in print, is copyrighted by the Informing Science Institute. Permission to make digital or paper copy of part or all of these works for personal or classroom use is granted without fee provided that the copies are not made or distributed for profit or commercial advantage AND that copies 1) bear this notice in full and 2) give the full citation on the first page. It is permissible to abstract these works so long as credit is given. To copy in all other cases or to republish or to post on a server or to redistribute to lists requires specific permission and payment of a fee. Contact Publisher@InformingScience.org to request redistribution permission. discuss and challenge the ideas of others, and work together towards a group solution to the given problem (Johnson \& Johnson, 1989). It has also been found that learning within a group helps students develop critical thinking skills, skills of self-reflection, and coconstruction of knowledge and meaning (Brindley, Walti, \& Blaschke, 2009). Similarly, Moller (1998) observed that groups have been found to outperform 
individual members of a learning community in higher-order thinking activities such as problem solving and critical thinking.

Collaboration in small groups has been particularly recognised as both advantageous and appreciated by students. It has been shown that small groups enable students to identify and correct misconceptions more easily and quickly and to improve understanding of the topics being studied (Gayatan \& McEwen, 2007). In addition, small groups are considered as more suitable for group discussions and equal contribution of group members (Finegold \& Cooke, 2006). Springer, Stanne, and Donovan (2009) found that small groups provide students with a better learning experience and ultimately greater academic achievement, whereas Brindley et al. (2009) reported that students often prefer working in small teams over large study groups.

Since one of the primary objectives of any educational institution is to enable its students to acquire knowledge and skills required for their future professional positions, it is of utmost importance for these institutions to synchronise their curricula and instructional approaches with trends and practices in workplace settings. Considered from the educational perspective, the major current trend in the workplace is an increased emphasis on the role of learning, where continuous learning and knowledge building are considered as one of the main responsibilities of any individual within an organisation (Meister \& Willyerd, 2010). Furthermore, the nature of work within organisations is changing from individual assignments to team-based activities and group work is becoming common in a variety of professions, especially in disciplines oriented towards design and development. In addition, as the work is becoming more and more geographically distributed, online collaboration among team members has become a regular practice. It has been shown that skills gained from the experience of collaborative learning are highly transferable to team-based work environments (Shaw, 2006). Accordingly, group work in university courses can be considered as an important preparation for future professional life (Smith et al., 2011).

Despite all the above mentioned advantages of collaborative learning, when collaboration is taking place in online learning settings students are often reluctant to participate actively. The main reasons for this reluctance include (but are not restricted to) the following (Brindley et al., 2009; Piezon \& Ferree, 2008; Wright \& Lawson, 2005):

i. a sense of not having full control over the quality of the group work and the subsequently assigned grade;

ii. concerns that there might be a group member with less than satisfactory performance for whom other members will have to compensate;

iii. time required for effective collaboration - group work requires students to stick to a particular schedule, thus reducing the flexibility and convenience of online learning.

In addition, it has been found that many students did not have a chance to experience collaborative work during their previous education and tend to perceive their colleagues as rivals (Sanders, 2008).

The observed difficulties of online group work are often a consequence of sub-optimal group formation. In fact, the creation of an optimal study group is a challenging task. Online students typically do not know each other prior to the course they are taking together and, due to the nature of the online learning environment, the socialisation process tends to last far longer than in traditional face-to-face learning settings. Therefore, even when students are given the option to form study groups on their own, it is difficult for them to do so. Instructors, on the other hand, often either have no knowledge about the online students enrolled in the courses they teach or are limited to information about the students' grades in the previous courses. That is far from enough knowledge for forming optimal learning groups since students differ in their personalities, learn- 
ing styles and collaboration skills. Therefore, instructors tend to randomly choose students for study groups (Roberts \& McInnerney, 2007).

In this paper, our main objective is to understand and explain the problems of effective group work from an Evolutionary Game Theory (EGT) perspective. EGT has been used extensively as a framework for studying the emergence and maintenance of cooperation in many disciplines (Axelrod, 1984; Maynard Smith, 1982; Nowak, 2006a). However, we are not aware of any previous studies applying the propositions of EGT for understanding and facilitating group collaboration in online learning settings. Aiming to investigate whether and to what extent EGT can be applied to explain students' participation in collaborative study groups, we have conducted an empirical study with students of an undergraduate online unit taught at a university in Australia. The study was also aimed at identifying students' perceived benefits and deficiencies of learning collaboratively within online study groups. Here, we present the design of the study and discuss the obtained results. In the concluding part of the paper, we highlight our plans to further explore issues surrounding online collaborative group work based on EGT.

Before proceeding to the detailed presentation of our research work, we would like to clarify the meaning of some terms that are used throughout the paper. First, we use the term unit to refer to a group of related lessons supported by a common goal or theme that a person may undertake within a department or faculty (another term often used to refer to the same thing, but not in this paper, is course). Second, we explicitly state that even though in the context of EGT we discuss mechanisms for establishing and maintaining cooperation, our focus is not on cooperative learning. In other words, the term cooperation in the context of EGT does not have the same meaning as in the context of education and group work. The research presented in this study is focused on collaborative learning. Although the terms cooperative and collaborative learning are sometimes used interchangeably, there are differences between the two approaches (Panitz, 1997) that we want to point out. Cooperative learning assumes the existence of a set of processes which direct students' group work towards the accomplishment of a specific learning goal. It is instructive in nature and closely controlled by the teacher. On the other hand, collaborative learning is more student-centered, in that students are in control of the group learning process and the teacher only assumes the role of a facilitator of the group work.

\section{Background}

In this section we summarise the two research areas related to our work, namely, evolutionary game theory and online collaborative learning.

\section{Evolutionary Game Theory}

Game theory was originally developed in economics to describe social interactions (see Von Neumann and Morgenstern, 1944). It offers an abstract framework of real-life situations where different interaction scenarios between individuals can be investigated. Two fundamental assumptions that underlie game theory are rationality and strategic interactions. A rational player is one who takes into account all the available information in a game and tries to maximise his or her payoff in the outcome of the game (Rapoport, Guyer, \& Gordon, 1976). However, it has been argued that the assumption of full rationality of players is unrealistic in practice (Binmore, 2007; Gintis, Bowles, Boyd, \& Fehr, 2005; Tomassini, 2008). Moreover, there seems to be a lack of dynamical view towards players with the controversial assumption of instantaneous interactions. In the real world, players observe their own behaviour and the behaviour of other players, and by learning more about the game and the environment over time they can adapt their strategies (Tomassini, 2008). 
In view of the above mentioned issues, standard game theory approaches have been extended by adding evolution as a new dimension (i.e., "evolutionary” game theory or EGT) thereby dropping the unrealistic assumption of rationality. To this end, the concepts of population of players and interpretation of payoff as fitness have been considered, which naturally lead to a dynamical approach (Cressman, 2003; Gintis, 2000; Hofbauer \& Sigmund, 1998; Nowak, 2006a; Weibull, 1995). Originating from the work of Maynard Smith and Price (1973), the fundamental idea of EGT is that evolution takes part in spreading the successful strategies/traits in the population. Such a process is done via frequency-dependent selection, which means the spread of a particular strategy/trait depends on the relative abundances of the types of players in the population.

Boosted by the seminal books of Maynard Smith (1982) and Axelrod (1984), EGT has been used extensively as a standard tool for understanding the emergence and maintenance of cooperation. Based on the development and study of different social dilemma games over the past few decades, several mechanisms that encourage cooperative behaviour within the general EGT framework have been identified. Nowak (2006b) reviewed and summarised five of the most relevant mechanisms as follows: kin selection, direct reciprocity, indirect reciprocity, network reciprocity (which is also a generalisation of spatial reciprocity), and group selection.

Among these mechanisms, one of the most important themes is the existence of group structures in the population (e.g., network/spatial reciprocity, group selection, or, to some extent, kin selection). Numerous studies in the EGT literature have demonstrated that by restricting the interactions of players to local neighbourhoods/groups (Chiong, Dhakal, \& Jankovic, 2007; Chiong \& Kirley, 2009, 2011, 2012a; Killingback \& Doebeli, 1996; Nowak \& May, 1992, 1993) or subdividing the population into groups (Killingback, Bieri, \& Flatt,, 2006; Nunney, 1985; Traulsen \& Nowak, 2006; Wilson 1990), cooperative behaviour can be promoted. Motivated by this, we hope to apply principles and findings from EGT to address issues in online study groups.

\section{Collaborative Learning in Online Groups}

The initial research findings related to online group work were predominantly optimistic (e.g., see McConnell, 2000; Stacey, 1999). This optimism stemmed largely from high expectations about the tools that Web-based learning platforms could offer for online collaborative learning (Jones \& Steeples, 2002). More recent studies have shown, however, that while the technology does provide a solid platform for online collaboration, it does not guarantee successful learning (Laurillard, 2002). Accordingly, a number of research studies were conducted with the aim of identifying the factors that influence (either positively or negatively) the success of collaboration in online study groups. In this section, we summarise the most important findings of those research studies.

One research stream explored students' perceptions about the benefits of online group work as well as the problems they experienced while studying as members of online learning groups. For example, Ellis (2001) reported the following positive aspects of online collaborative work: 1) access to peer knowledge, 2) availability of other students to provide feedback, 3) ability to access the technology at one's convenience, and 4) an opportunity to reflect on the exchanged messages. Gabriel (2004) reported that the students participating in her study developed an understanding of the recursive nature of knowledge construction (review, rethink, and revise one's work) and an increasing belief in their own ability to learn efficiently in the online group environment (i.e., their perception of self-efficacy increased as the course progressed).

Researchers also reported on the identified weaknesses and challenges of online collaborative work. For instance, Stodel, Thompson, and MacDonald (2006) identified five themes regarding what learners perceived were missing from their online learning experience, namely, robustness of online dialogue, spontaneity and improvisation, perceiving and being perceived by the other, 
getting to know others, and learning to be an online learner. Finegold \& Cooke (2006) found that group members not participating in group discussions and not contributing equally towards the completion of group tasks were the most prominent concerns experienced by students, whereas active participation was regarded as the most important factor influencing the success of online groups. Similar findings have been reported in earlier related studies (e.g., see Vonderwell, 2003). Gabriel (2004) found that one of the major challenges experienced by her students was the time required to prepare their responses to other group members. For some students, the imposed work schedules posed a problem too, particularly during small virtual group activities (Gabriel, 2004).

Finegold \& Cooke (2006) found that for many students, important success factors of online group work included an atmosphere of trust and respect, shared objectives, and being supportive to other group members. In addition, group working skills, such as decision making, consensus building, and dealing with conflict, were strongly favoured by many students. Again, these findings were consistent with findings reported in earlier work (e.g., Gabriel, 2004; Palloff \& Pratt, 2001).

Another important determinant of successful group work is the group formation process. In particular, group formation is found to play a critical role in enhancing the success of collaborative learning (e.g., Johnson \& Johnson, 1990; Slavin, 1983). It was also identified as one of the primary sources of unsuccessful outcomes of group work (e.g., Johnson \& Johnson, 1985). Likewise, Roberts \& McInnerney (2007) identified group formation as one of the most significant challenges of online group learning and suggested either random selection of group members or intentional creation of heterogeneous groups as approaches to address this challenge. Both approaches have been widely applied and both have their specific advantages and disadvantages.

Previous research has demonstrated numerous advantages of heterogeneous groups (e.g., Kagan, 1997; Johnson \& Johnson, 1989). However, the creation of heterogeneous groups can be a rather time and effort intensive task (for the collection and analysis of students' data) and sometimes is even not possible (due to the lack of data about students' characteristics). Furthermore, even when comprehensive student data are available and used for the group formation, this is not a guarantee of group success and student satisfaction. For example, in the study reported by Smith et al. (2011), even though the instructor assigned students to groups by considering a number of their characteristics (skills, work habits, expectations of grade, physical location, and employment background), students reported a number of problems and dissatisfaction with the group work. Therefore, Roberts \& McInnerney (2007) suggested random selection as the group formation mechanism; in many cases it has proven to be as effective as more sophisticated approaches (e.g., Huxham \& Land, 2000).

Allowing learners to form their own groups or select their own topics facilitates the socialisation within groups and positive group dynamics (Juwah, 2006). It also increases students' feeling of ownership of and responsibility for the group task and thus positively influences their motivation to engage in the group work (Brindley et al., 2009). On the other hand, other researchers have found that when given a chance to create groups on their own, students form groups that perform poorly in terms of collaboration and learning through knowledge sharing and co-construction (Oakley, Felder, Brent, \& Elhajj, 2003). Obviously, group formation is still an under-explored topic and deserves further attention of the research community.

\section{Methods}

\section{Research Questions}

In our study we focused on the following research questions: 
RQ1: What do students perceive as advantages and disadvantages of online collaborative learning?

RQ2: Can the perceived advantages and disadvantages of online collaborative learning explain the observed level of students' participation in online group collaboration?

RQ3: Can Evolutionary Game Theory be used to explain students' level of participation in online group collaboration?

\section{Study Design}

This section briefly describes the design of the study we organised in order to explore our research questions. The details of the study design are further elaborated in the following sections.

The study was organised in the context of a programming unit taught at a university in Australia. The students were undergraduates taking a major or minor in business and information systems or information technology. The unit's content focused on the effective design and development of software products. Students could also acquire some hands-on experience in building software products using the specific programming language taught in the unit. The unit was fully online, and all the communications and interactions among students within their study groups were done through the discussion board and email services of the university's Learning Management System.

The students enrolled in the unit were assigned five assessment tasks that they had to complete during the study period. Two of those tasks (Tasks 2 and 4) had to be done in a collaborative manner. As for the other two tasks (Tasks 1 and 3), the students were required to document their experiences in and reflections on the group work done around the collaborative tasks; the final task (Task 5) was the final exam that was done individually. To pass the unit, the students were required to do all five assessment tasks and have a minimum aggregate score of $50 \%$ of all tasks' marks. For the collaborative tasks (Tasks 2 and 4), the students were organised in small groups. Details on the group formation process are given in the following section, while the assessment tasks are more thoroughly described in the Study Protocol section.

\section{Participants and Group Formation}

The study participants were undergraduate students enrolled in a 13-week programming unit during the third study period of 2011. There were 193 enrolled students in total. The students were adults, and the majority of them were employed (a minority were either retirees or stay-at-home mothers). For most of the students this was not the first online unit they had taken, meaning that they had prior experience with online learning but not necessarily with online group work. In addition, the majority of the students had experience with collaborative face-to-face learning.

For the collaborative assignments, the students were organised into small study groups, each group having 5-8 participants (the variations were partly due to students withdrawing from the unit after the first few weeks, i.e., before their enrollment "cut-off” date). There were 32 groups all together. Each group had a teaching staff attached to it; specifically, there were three instructors, each one responsible for around 10-12 groups. The instructors took the role of facilitators of the group work. In this capacity, their roles might include giving a particular group a push when the group was "quiet", answering questions directed to them, and so forth. They were neither in the role of actively moderating students' work, nor were they initiating/directing each group's work. Instead, it was left to the students to decide whether and to what extent they were going to participate in the group and how they were going to organise the group's work. There were no specific requirements or expectations regarding the students' behaviour in the collaborative learning situation; they were just told, at the beginning of the unit, that they were expected to behave 
as if they were in their real work environment (e.g., following the common workplace protocols in engaging with others, showing mutual respect, and resolving conflicts when necessary). There was, however, a requirement regarding the minimal level of participation: each student was expected to have at least 10 group participation actions (these included collaboration sessions, discussion thread messages, file and email exchanges). Even though the students were required to work together on the collaborative tasks, each student was obliged to submit his/her own assignments.

Initially, the groups were formed by randomly assigning students to different groups. After the completion of Tasks 1 and 2, the groups were "remixed" by moving some of the students from their existing group to a new group (note: the students were not told beforehand that remixing would take place). Specifically, active participants (i.e., students meeting the minimum participation actions requirement AND submitting their reports for the assessment tasks) were moved to join other active participants in other groups - these groups typically had more than 50\% or $75 \%$ active participants. In return, non-participants from those groups were moved to fill up the vacant places of the "moving" active participants' original groups. This remixing method was inspired by some of the "migration" schemes from the literature of EGT, such as success-driven migration (Helbing \& Yu, 2008, 2009), adaptive migration (Jiang, Wang, Lai, \& Wang, 2010), aspirationinduced migration (Lin, Yang, Wu, \& Wang, 2011; Yang, Wu, \& Wang, 2010) or the simple "walk-away" move (Aktipis, 2011). Success-driven migration is based on the idea that individuals would choose to move to groups with higher expected payoffs. Adaptive migration allows individuals to make use of local information (e.g., the proportion of non-cooperators in a group) in deciding whether or not to move. Aspiration-induced migration means that individuals will move to a new group if their payoff is below a certain aspiration level. The simple "walk-away" strategy enables individuals to leave their group if they cannot gain high returns (due to too many non-cooperators) in the group. All these migration schemes have been shown to enhance the extent of cooperative behaviour in the EGT domain.

\section{Study Protocol}

Figure 1 illustrates the sequence of assessment tasks as they were assigned to and done by the students during the study period. We now describe both the assessment tasks that required students' collaboration within online study groups (Tasks 2 and 4) and the tasks that required them to report their experiences with online collaborative learning (Tasks 1 and 3). Task 5, the final exam, is not further described as it does not relate to the research questions.

For Task 1, the students were requested to write a report (1500 words) about their experiences with the collaborative group work done in the scope of Task 2 (note: these two tasks ran in parallel). In particular, they were asked to the following: write about why they did or did not take part in the group work; give a simple summary of all the actions they took as part of their participation; propose and discuss some strategies that could be applied in a group situation to respond to misunderstandings among group members; state the topics for which they got assistance by other group members or the artifacts of fellow students' work, as well as the topics where they or products of their work helped other group members; and finally, provide their personal reflection about their own experience of participating in the group. This assignment was accounted for $5 \%$ of the final mark.

Task 2 was a report (also 1500 words) on software development models and represented 20\% of the final mark. For this task, the students were required to write about their recommended programming approach and software development methodology for a chosen scenario. They were also asked to write about two approaches/methodologies that were not suitable for the chosen scenario. 


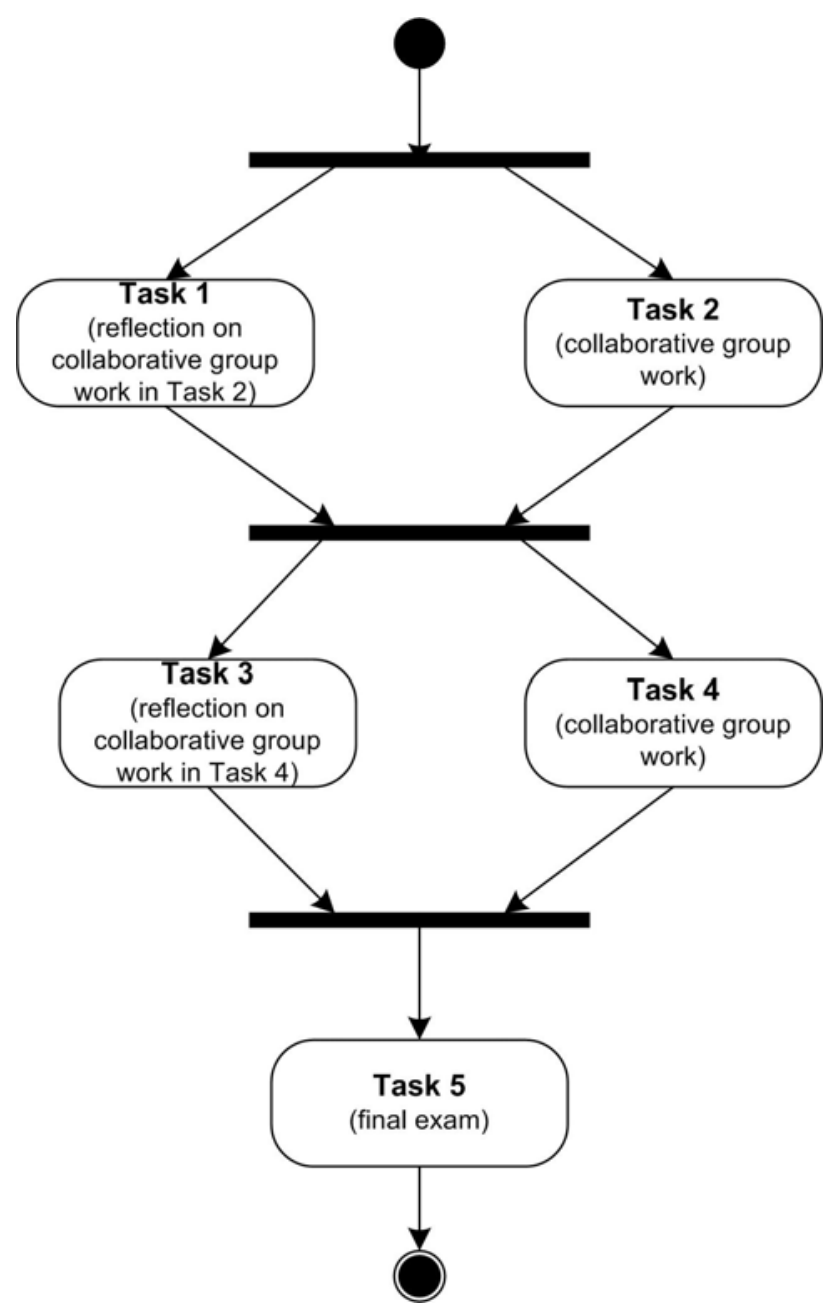

Figure 1 The sequence of study tasks during the study period

Task 3 was largely identical to Task 1; the only variation was that the students were required to write about their experiences with and reflections about the collaborative work done in the scope of Task 4 rather than Task 2 (note: Tasks 3 and 4 ran in parallel).

Task 4 was the most challenging one and thus contributed 25\% to the final mark. It was a software development project for which the students needed to develop a Web application using the specific programming language they had learned in the unit. They were allowed to use pieces of code written by fellow students from the same group (the rationale of this was to promote code reuse), with the condition that they had to clearly acknowledge the sources. This task overlapped in time with Task 3 - the students' reflections on the collaboration that took place around the software development project.

As stated in the previous section, a portion of the students were moved from their existing group to a new group after the completion of Tasks 1 and 2, so the study groups working on Task 2 were not entirely the same (although some groups still kept the majority of their old members) as those working on Task 4. 


\section{Data Analysis}

To answer our research questions, we analysed reports that the students wrote for Tasks 1 and 3 (i.e., the assignments requiring them to reflect upon the group work experience). In addition, we made use of the data about their participation level in each collaborative task (i.e., Tasks 2 and 4).

Specifically, to explore our research questions we needed to:

i) assess the activity level of all study groups; and

ii) identify the common reasons the students reported for participating or not participating in online study groups (i.e., the perceived advantages and disadvantages of online collaboration).

The assessment of a group's participation level was based on two criteria:

i) The total number of participation actions in a group. Participation actions include collaboration sessions, file exchange, group discussion board and emails. To determine their number for each group, we made use of students' self-reports on performed participation actions - students were required to include this information in the reports they wrote for Tasks 1 and 3.

ii) The percentage of active participants in a group. A group member is considered to be an active participant if he/she met the minimum participation actions requirement (i.e., had at least 10 participation actions) and submitted his/her reports for Tasks 1 and 3.

Following these criteria, we assessed the participation level of all study groups and then classified each group into one of the following three categories: Active, Borderline and Inactive. The classification was driven by the following rules:

- A group was considered as an Active group, if there were more than 100 participation actions among the group members and more than $75 \%$ active participants in the group.

- In a Borderline group, there were between 50-100 participation actions among the group members and around $50 \%$ of active participants in the group.

- The rest were categorised as Inactive groups.

To identify the common reasons for students' participation or lack of participation, we performed a detailed content analysis of the students' reflections on advantages and disadvantages of online group work (these reflections were part of the reports they wrote for Tasks 1 and 3). However, since it was not feasible to analyse in detail the reports of members of all 32 study groups (i.e., all students), we decided to randomly select three groups from each category (Active, Borderline and Inactive) and do content analysis of the reports submitted by their members.

First, we analysed a small subset of students' reports, looking for recurring themes that could be used as a coding scheme. The identified themes are presented in the first column of Table 1 and Table 2; these themes were then used to code the reports submitted by the members of the 9 sample groups. The unit of analysis for coding was either a sentence or a set of sentences expressing a student's perception of some aspect of group work.

\section{Results and Discussion}

In this section, we present and discuss the study results from the perspective of the previously introduced research questions. 


\section{The Perceived Advantages and Disadvantages of Online Collaborative Learning}

Table 1 presents the common themes that we identified in the students' perceptions of the advantages of online collaborative work. For each theme, the table gives a few illustrative students' comments.

Table 1 Reasons that the students cited for participation in online collaborative group work

\begin{tabular}{|c|c|}
\hline \multirow{2}{*}{$\begin{array}{l}\text { Peer (social) } \\
\text { support }\end{array}$} & $\begin{array}{l}\text { "Studying online is very much a lonely activity, so having a group there that are ex- } \\
\text { periencing the same challenges that I can talk to and receive support from would help } \\
\text { keep me motivated and goal oriented" }\end{array}$ \\
\hline & $\begin{array}{l}\text { "There were several threads in the group discussion board where individuals were } \\
\text { posting up information about themselves and how they are reacting to the workload } \\
\text { and it was reassuring knowing that I wasn't alone" }\end{array}$ \\
\hline \multirow[t]{2}{*}{ Networking } & $\begin{array}{l}\text { "Group work is an excellent way to build a professional network. Networks are bene- } \\
\text { ficial by exposing you to people and corporations that you may not have been exposed } \\
\text { to otherwise. It helps build your personal "brand" and can assist with employment or } \\
\text { projects." }\end{array}$ \\
\hline & $\begin{array}{l}\text { "The social aspect of participating in the group presented a convenient way for me to } \\
\text { become acquainted with a manageable amount of fellow students that I could have } \\
\text { meaningful dealings with" }\end{array}$ \\
\hline $\begin{array}{l}\text { Commitment to } \\
\text { and responsibility } \\
\text { towards group } \\
\text { members }\end{array}$ & $\begin{array}{l}\text { "By planning work to keep up with a group, usually the work is done on time as other } \\
\text { people may rely on it. This relates to the "fitness with a friend" phenomenon, where- } \\
\text { by people will skip a fitness session if they are going solo, but participate if they were } \\
\text { doing it with a friend so they would not let them down" }\end{array}$ \\
\hline \multirow{2}{*}{$\begin{array}{l}\text { Social comparison } \\
\text { and competition }\end{array}$} & $\begin{array}{l}\text { "It is a belief of mine that life is a competition. Many strive their best and rank where } \\
\text { finish against their peers. Competition can improve your performance simply by push- } \\
\text { ing you to improve your own results." }\end{array}$ \\
\hline & $\begin{array}{l}\text { "Help judge the pace at which others were moving through the learning materials and } \\
\text { objectives" }\end{array}$ \\
\hline \multirow{3}{*}{$\begin{array}{l}\text { Preparation for } \\
\text { workplace team } \\
\text { work }\end{array}$} & $\begin{array}{l}\text { "Working in a smaller group prepares you for any business situation as you will never } \\
\text { really work by yourself as a programmer and its vital to develop your communication } \\
\text { skills and helping others where needed that the team can succeed as a whole" }\end{array}$ \\
\hline & $\begin{array}{l}\text { "Another appealing aspect of the group format was that it likely approximated some } \\
\text { of the group work situations that I would encounter upon attaining employment in the } \\
\text { IT field" }\end{array}$ \\
\hline & $\begin{array}{l}\text { "I wanted to participate in my Discussion and Support group to gain experience in } \\
\text { working as part of a team, so that when I enter the workplace I am more able to work } \\
\text { with other people." }\end{array}$ \\
\hline \multirow{4}{*}{$\begin{array}{l}\text { Social learning } \\
\text { (learning through } \\
\text { discussion and } \\
\text { sharing of ideas, } \\
\text { concerns and } \\
\text { knowledge) }\end{array}$} & $\begin{array}{l}\text { "The opportunity to communicate with fellow students, discuss strategies and share } \\
\text { ideas" }\end{array}$ \\
\hline & "Learn from other group members (e.g., skills, experiences)" \\
\hline & $\begin{array}{l}\text { "A team environment where members can act as a soundboard and you can relay } \\
\text { problems, ideas, tips, etc. with each other" }\end{array}$ \\
\hline & "Encourages feedback loops based on peer review" \\
\hline \multirow[b]{2}{*}{ Peer help } & $\begin{array}{l}\text { "Participating in the Discussion and Support Group has allowed me to find assistance } \\
\text { where I need it" }\end{array}$ \\
\hline & $\begin{array}{l}\text { "The forums and smaller groups provide a sounding board, which in some cases less- } \\
\text { en the anxiety felt by students, who at times may feel lost due to the subject matter } \\
\text { being studied or particular assessment events." }\end{array}$ \\
\hline \multirow{2}{*}{$\begin{array}{l}\text { Different points } \\
\text { of view }\end{array}$} & $\begin{array}{l}\text { "The opportunity to see how other people view issues can enlighten and broaden your } \\
\text { own point of view. Perhaps they see an angle that you didn't, thus expanding your } \\
\text { knowledge and understanding." }\end{array}$ \\
\hline & $\begin{array}{l}\text { nally, I recognised that each member would bring their own unique set of } \\
\text { ge and abilities to the group." }\end{array}$ \\
\hline
\end{tabular}




\begin{tabular}{|l|l|}
\hline \multirow{4}{*}{ Unit requirement } & "It's a requirement" \\
\cline { 2 - 2 } & $\begin{array}{l}\text { "Participation constitutes a key component for the successful completion of the as- } \\
\text { sessment tasks" }\end{array}$ \\
\cline { 2 - 2 } & "The assessment tasks contribute marks to the final grade" \\
\hline $\begin{array}{l}\text { Previous positive } \\
\text { experience }\end{array}$ & $\begin{array}{l}\text { "Participated in support/discussion groups and discussion boards in previous units } \\
\text { and have found them to be helpful on many levels" }\end{array}$ \\
\hline
\end{tabular}

Many recognised themes overlap with those found in previous related studies. For instance, social learning (i.e., learning through communication and knowledge exchange) and closely related benefits of being exposed to different points of view were reported in, e.g., Gabriel (2004) and Finegold \& Cooke (2006); whereas Ellis (2001) reported on students' appreciation of peer help. However, we have also found some interesting students' observations that have not been identified as common themes in the previous research studies that we explored. These include, for instance, social comparison and competition. In particular, some students found that group learning settings allow for comparing their pace of work and progress towards the task objectives with those of their group members; likewise, group work on a study task was considered as a good preparation for the competitive environment that students are expecting to face in workplace and in daily life, in general. We believe that this feeling of competiveness was present because -although they worked in study groups - the students were required to submit their assignments individually.

The common themes that students cited for their reluctance to participate in collaborative group work were significantly less diverse than the identified advantages. These themes, along with a few most representative students' comments, are presented in Table 2.

Table 2 Reasons for students' reluctance to participate in online collaborative group work

\begin{tabular}{|c|c|}
\hline \multirow{4}{*}{$\begin{array}{l}\text { Low or no participation } \\
\text { of other group members }\end{array}$} & "Finding out that others are not willing to co-operate on the same level" \\
\hline & $\begin{array}{l}\text { "Spend the time to participate with group and people don't take the time to } \\
\text { respond" }\end{array}$ \\
\hline & "Hard to maintain consistent participation" \\
\hline & "Lack of participation from other members due to lack of time or interest" \\
\hline $\begin{array}{l}\text { Conc } \\
\text { "free }\end{array}$ & $\begin{array}{l}\text { "It can also be harder when only some members participate leaving others to } \\
\text { have to make more of an effort" }\end{array}$ \\
\hline \multirow{3}{*}{$\begin{array}{l}\text { Time constraints } \\
\text { (due to commitments in } \\
\text { personal and profes- } \\
\text { sional life and the time } \\
\text { required for active } \\
\text { group participation) }\end{array}$} & $\begin{array}{l}\text { "To participate in the support group every day is bit too hard for me, as I have a } \\
\text { full time job and study } 2 \text { subjects in this session, time management is one of the } \\
\text { big issue for me." }\end{array}$ \\
\hline & $\begin{array}{l}\text { "The key disadvantage of participating in the support group is the additional } \\
\text { time required monitor discussions and remain active within the group" }\end{array}$ \\
\hline & $\begin{array}{l}\text { "... the time taken to actively participate in an additional forum is not available } \\
\text { to all students." }\end{array}$ \\
\hline $\begin{array}{l}\text { Differences in } \\
\text { skill/knowledge level } \\
\text { of group members } \\
\end{array}$ & $\begin{array}{l}\text { "Not everyone will participate, and if some do, it may not be in the same capacity } \\
\text { that you may have expected." }\end{array}$ \\
\hline $\begin{array}{l}\text { The lack of socia } \\
\text { connections }\end{array}$ & $\begin{array}{l}\text { "Not knowing individuals involved in the group and/or their willingness to par- } \\
\text { ticipate" }\end{array}$ \\
\hline $\begin{array}{l}\text { Delays in } \\
\text { communication }\end{array}$ & "Hard to get a response from others in a timely fashion" \\
\hline $\begin{array}{l}\text { Reluctance to commit to } \\
\text { yet another social } \\
\text { channel }\end{array}$ & $\begin{array}{l}\text { "Personally I think the discussion group is a great idea, however it also becomes } \\
\text { an extra effort for students to commit. For example the Blackboard has the gen- } \\
\text { eral discussion on topics and assessments, as well Facebook... Facebook it's } \\
\text { easier to access and look for information as students are regularly on the social } \\
\text { network." }\end{array}$ \\
\hline
\end{tabular}


Similar to the findings of previous studies in this area (e.g., Finegold \& Cooke, 2006; Vonderwell, 2003), the majority of the students' comments reflected their concern about the level of participation of other group members. A related, albeit not very prominent, theme is the students' concern about the so-called "free riders", i.e., students who do not put much effort in the group's work but reap the benefits of the work done by the other group members. We believe that this theme, frequently found in previous similar studies (e.g., Brindley et al., 2009; Roberts \& McInnerney, 2007), was not as prevalent in our study because the students were required to write and submit their assignments individually. Another related theme is the difference in the observed skills and/or knowledge of the group members leading to an inability of group members to contribute at the same level; again, this is consistent with the findings of some previous studies (e.g., Piezon \& Ferree, 2008; Roberts \& McInnerney, 2007).

The impediments to group work caused by the employed technology, specifically asynchronous online discussion channels, were also reported by many students as the reason for their lack of participation. The importance of timely responses and synchronous means of communication is further acknowledged in the students' suggestions for improving the group work - a significant number of suggestions were related to the availability of different communication channels, especially voice communication, for interactions among group members.

The lack of social connections and, thus, the establishment of the feeling of mutual trust were also recognised by the students as something that negatively influenced their level of participation in the group work. This is fully consistent with the previous research work that has explored the role of social presence in online learning settings (Garrison \& Arbaugh, 2007).

Reluctance to commit to (yet) another social channel is a theme that we did not observe in the previous similar studies, but something to be expected since the majority of today's students are used to communicating and sharing ideas, information, and digital resources over general-purpose online social networks such as Facebook. Commitment to another social network requires additional time and attention that they are not easily willing to devote.

\section{The Perceived Advantages and Disadvantages of Online Group Work and the Students' Participation Level}

Our second research question (RQ2) was aimed at exploring whether some of the advantages and disadvantages of online group work perceived by the students could explain the students' level of participation in collaborative group work (in the scope of Tasks 2 and 4). To address this research question, we first computed the number of active and inactive participants in each study group, and then classified all groups into Active, Borderline or Inactive categories. All the computations were done following the rules given in the Data Analysis section.

Figure 2 presents the percentages of Active, Borderline and Inactive groups. The figure clearly shows that the Active groups constituted around only $22 \%$ of all the study groups. This was despite the themes of perceived advantages dominating over perceived disadvantages (as shown in the previous section). We tried to understand this low participation level by comparing students' perceptions of pros and cons of online group work across the groups of different participation levels. 


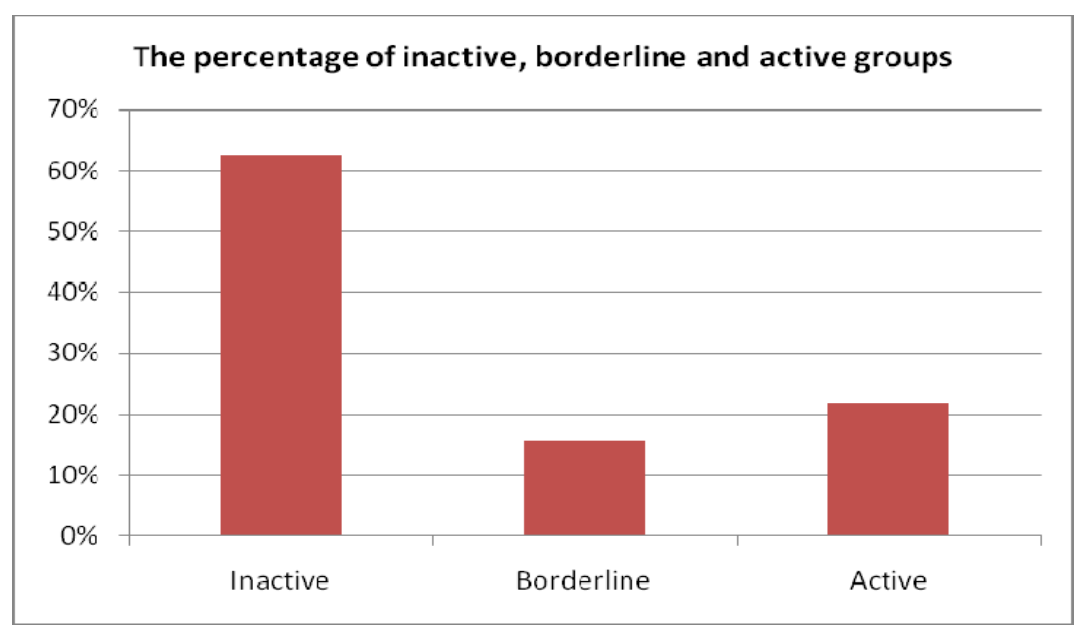

Figure 2. The percentages of inactive, borderline and active groups

By analysing the common themes identified in each category of study groups, we observed the following:

- In the Active groups, the occurrence of positive themes (i.e., themes given in Table 1) was considerably higher than the occurrence of negative ones (i.e., themes given in Table 2 ); more precisely, the ratios of positive vs. negative themes in the three Active groups were $3: 1,14: 1$ and $13: 1$ respectively.

- In the Borderline groups, positive and negative themes were almost equally present, though positive themes had higher occurrence in all three Borderline groups (the positive vs. negative themes ratios were $5: 4,11: 9,18: 11$ ).

- In the Inactive groups, contrary to the expectations, positive themes were dominant in two of the three groups (the positive vs. negative themes ratios were 1:3, 7:5, 18:5). Nonetheless, it should be noted that the majority of positive comments written by the members of these groups were not related to the students' actual experience, but to the expectations they had from the group work, i.e., the advantages they expected to have (but not realised) by participating in the group work.

By comparing and contrasting the occurrence of the common themes across the group categories, we found that the dominant positive and negative themes differed, though not significantly, across the three group categories:

- Only in the Inactive groups, Unit requirements was a frequently present positive theme (i.e., the perceived benefit from participation in the group work); in other words, for the majority of members of the Inactive groups, one of the primary reasons for the participation was to get some extra points contributing to the final grade.

- In all the considered groups (regardless of their activity status), two frequent positive themes were Social learning and Peer help, though they were particularly dominant in the Active and Borderline groups. This means that the students attributed high value to group discussions, exchange of ideas, information and knowledge, and mutual peer help. In addition, members of the Active and Borderline groups also recognised and valued the benefits of Peer (social) support, that is, the support that group members provide when a member is experiencing any kind of personal problem or challenge.

- Regarding the negative themes, by far the most dominant one in the Inactive groups was the Lack or low participation of other group members. In fact, all members of the three 
considered Inactive groups cited this as the main rationale for their dissatisfaction with the group work. Especially disappointed were those students who applied different strategies to try to "activate" their group members but without any success. This problem was present in the other two group categories, as well, but to a far lesser extent.

- A frequently co-occurring negative theme in all three groups was Time constraints (including the time required for active group participation). This points to the students' recognition that group work requires a commitment to frequent exchanges with group members, demanding a considerable amount of time (partially due to the asynchronous nature of the used discussion channels). Since a significant number of students were taking this unit in parallel with their job, they found it challenging to devote the time required for sustaining group interactions.

Based on the above stated findings, we can conclude that:

- The major reason for students' decision to retreat from online group work was the lack of or low participation of other group members; this is coupled with the fact that the majority of the students who participated in this study had regular jobs, and that active participation in group work required a considerable amount of time.

- The primary reasons for active participation in group work were the perceived benefits of social learning, peer help, and peer support; in addition, the participation of a substantial number of students was extrinsically motivated by the prospect of getting a higher final grade.

\section{Evolutionary Game Theory and Online Group Collaboration}

Our third research question (RQ3) concerned the use of EGT to explain students' level of participation in online group collaboration. Based on the results and findings from the previous sections, it is clear that online study groups did not work as effectively as anticipated in our case. The low percentages of active participants in Tasks $1 \& 2$ and Tasks $3 \& 4$ can be observed in Figure 3 a) and b) respectively.

The percentages of active paticipants and non-participants in Tasks 1 \& 2

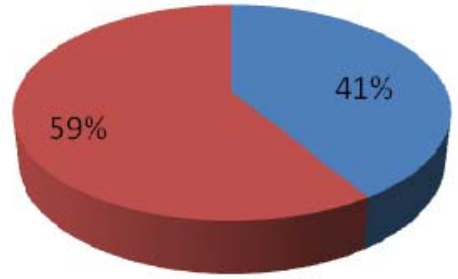

active particioants non-particioants

a)
The percentages of active paticipants and non-participants in Tasks $3 \& 4$

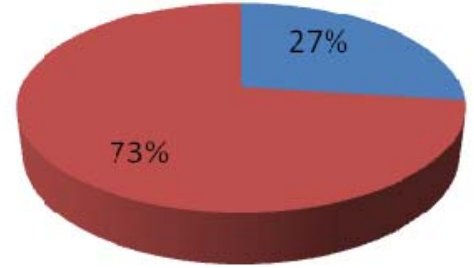

active participants non-participants

b)

Figure 3 The percentages of active participants and non-participants in: a) Tasks 1 \& 2 (i.e., before the remixing of study groups); and b) Tasks $3 \& 4$ (i.e., after the remixing of study groups)

We now frame the issues surrounding the lack of participation in online study groups using two widely used theoretical models in EGT: the Prisoner's Dilemma (PD) and Snowdrift (SD) games. These models embody situations characterised by different degrees of conflicting interests between individuals and are typically represented in the form of two-player, two-strategy (i.e., $2 \mathrm{x}$ 2 ) games. The two strategies (or actions) involved are cooperate and defect. 
In a PD game, a reward (R) is given when both players choose to cooperate, whereas a punishment $(\mathrm{P})$ will be handed out if they both defect. In the situation where one player defects and the other player cooperates, the one who defects is awarded a tempting reward $(\mathrm{T})$ but the one who cooperates is given the sucker's punishment (S). Accordingly, we have the inequalities $\mathrm{T}>\mathrm{R}>\mathrm{P}$ $>\mathrm{S}$, which imply that individually the best strategy is to defect. However, an additional constraint $2 \mathrm{R}>(\mathrm{T}+\mathrm{S})$ is usually imposed, meaning that the collectively best strategy is to cooperate (hence the dilemma).

Table 3 illustrates the game in terms of costs and benefits to the players. On one hand, a cooperative act results in a benefit $b$ to the opposing player but a cost $c$ to the cooperator. Here, $b>c>0$. Defection, on the other hand, incurs neither costs nor benefits. This means if the opponent cooperates, a player gets the reward $\mathrm{R}=b-c$ if he or she also cooperates, but can do even better and get $\mathrm{T}=b$ by defecting. If the opponent defects, however, a player gets the lowest payoff $\mathrm{S}=-c$ for being cooperative, and $\mathrm{P}=0$ for being non-cooperative. In either case, it is clear that defection is the better choice regardless of what the opponent plays.

Table 3 The payoff matrix of a 2 x 2 PD game

\begin{tabular}{|l|c|c|}
\hline & Cooperate & Defect \\
\hline Cooperate & $b-c$ & $-c$ \\
\hline Defect & $b$ & 0 \\
\hline
\end{tabular}

While the PD game reflects a social dilemma in the strictest sense, the SD game relaxes some of these constraints by (1) allowing players to obtain some immediate benefits from their cooperative acts and (2) sharing the cost of cooperation between cooperators. Table 4 depicts the payoff matrix of a two-player SD game. Again, $b>c>0$. The fundamental difference between the payoff matrices of the two games is that in the SD game, cooperation is the better option than defection when the opponent defects. In other words, instead of $\mathrm{T}>\mathrm{R}>\mathrm{P}>\mathrm{S}$ as in the PD, the SD game has $\mathrm{T}>\mathrm{R}>\mathrm{S}>\mathrm{P}$.

Table 4 The payoff matrix of a 2 x 2 SD game

\begin{tabular}{|l|c|c|}
\hline & Cooperate & Defect \\
\hline Cooperate & $b-c / 2$ & $b-c$ \\
\hline Defect & $b$ & 0 \\
\hline
\end{tabular}

The SD game can be easily illustrated using the example of a group assignment: You and your fellow student have been assigned to work together on a task within the same group. At the end of the task, both of you have to write a single report and submit it for assessment. The score given to the report will be the mark you get for the assignment. If both of you share the work on an equal basis, the amount of work required to complete the job is slashed into half. However, if your partner refuses to work on the task, it is still a wiser choice for you to complete the job on your own (or you risk getting nothing) even though you have to bear the cost of doing all by yourself. Your partner, while not contributing anything, gets the same benefit as you in the end.

In our case, the students were required to submit their individual report for each of the tasks. This brings us closer to the PD game than the SD game. More precisely, if we consider $b$ to be the shared information, ideas, and resources (e.g., files) contributed by active participants, $c$ the cost of them doing so plus writing up the reports (for Tasks $1 \& 2$ ) or a report and software (Tasks $3 \&$ 4 ), and $w$ the mark they get for each completed task, we have the following payoff structure: 
Table 5 The payoff matrix of a tailored $2 \times 2$ PD game

\begin{tabular}{|l|c|c|}
\hline & Cooperate & Defect \\
\hline Cooperate & $b+w-c$ & $w-c$ \\
\hline Defect & $b$ & 0 \\
\hline
\end{tabular}

The interpretation is as follows: a student who did not participate actively could still access the shared information, ideas and resources (i.e., $b$ ) posted by an active participant in the discussion board or file exchange area without needing to bear any cost. Obviously, the non-participant would not get any mark (i.e., $w$ ) for not submitting his work (but he could still benefit from the information gained for the final exam). The active participant would receive a reasonable mark while contributing (i.e., $w-c$ ), but unless the other student had actively contributed (i.e., $b+w-$ $c$ ) he would not get anything new apart from the things he himself contributed. When there were no active participants between them, none of them would get anything (i.e., 0 ).

Recall that in Tasks 1 \& 2, the students were required to write 1500-word reports for both tasks. Task 1 was worth only 5\% of the overall mark, while Task 2 worth $20 \%$. Similarly, in Tasks 3 \& 4 the students were required to write a 1500 -word report and a software application respectively, with the weight for the former $5 \%$ and the weight of the latter $25 \%$. Let us assume that the cost of completing Tasks $2 \& 4$ is the same as the total mark available for each of the tasks. This means most of the time the cost the students pay for doing the tasks would exceed the mark they expect to get (i.e., $c>w$, since hardly anyone gets full mark for report writing and software application), and thus lands us right into the region of a PD game with $\mathrm{T}>\mathrm{R}>\mathrm{P}>\mathrm{S}$. From here, it is not difficult to derive that low levels of participation would be inevitable.

Based on the above understanding, we could draw principles and findings from EGT to enhance the level of participation. Our endeavor in remixing students of different groups between Tasks 1 \& 2 and Tasks $3 \& 4$ was one of the attempts we made in this unit. Inspired by the study by Aktipis (2011) showing a simple "walk-away" strategy that allows individuals to leave their group if they cannot gain high returns (due to too many defectors) in the existing group as well as other studies (Helbing \& Yu, 2008, 2009) demonstrating that success-driven migration can cause outbreak of cooperation, we moved active participants from Inactive groups to Active groups and combined active participants from two Borderline groups into one. In return, non-participants from Active groups were moved to Inactive groups to fill up the vacant places left by the "moving” active participants, and non-participants from Borderline groups were combined to make up new groups.

By doing this, we were hoping that (1) more Active groups could be formed; and (2) Inactive groups could be "revived" (e.g., when there were no active participants in the group, nonparticipants might step up to become active participants). Unfortunately, the remixing method worked only for those who had been moved to Active groups. This was evident based on the following sample comments from the "moving" students:

"In the second half of this unit, from week 7 onwards, I have found participating in this group more useful that the first half. I found myself in a new group and before I could post a "hello" message I was already sent a nice welcoming email from one of the other members who noticed I was a new member and wanted to welcome me into the group. This greatly assisted with interacting with the rest of the group. Once I had been introduced it was easy to get straight into the collaboration."

"My previous decision was to participate in the group and I have continued to do so. Being moved to the new group has helped to make this decision. Previously, I listed the lack of participation from the previous group as a major disadvantage. After being moved to Support Group 6, I immediately noticed an active discussion board and believed this would help overcome a large issue of group participation." 
The non-participants in Inactive groups, however, remained inactive.

\section{Conclusion and Future Work}

In this paper, we have presented a research study that was aimed at getting a better understanding of students' participation and engagement in online collaborative group work. We approached this research objective from two perspectives. The first one, which could be characterised as "traditional/conventional”, relied on an analysis and comparison of advantages and disadvantages of online collaborative learning as perceived by students. The second one, which we consider to be new and innovative, relied on the application of EGT. The results we obtained by following the former perspective were consistent with the findings reported in previous studies focused on the same research topic. In particular, we found that the lack of or low participation of other group members was the major reason for students' decision not to participate or to reduce their participation level; another commonly cited obstacle was time constraints (imposed by personal life and job commitments) coupled with the students' recognition that active group participation requires devotion of a significant amount of time. As for the observed advantages of online study groups the main drivers of students' participation - we recognised the perceived benefits of social learning, peer help, and peer support; in addition, the ability to directly improve their final grade through group participation (by getting points on the assignments that demanded group collaboration) was also a highly common motivator among the students.

Even though the exploration of the students' perceptions of pros and cons of collaborative groups gave us some beneficial insights, we were primarily interested in the employment of EGT to try to understand the observed level of students' participation in group work. We found that Prisoner Dilemma, a widely used theoretical model in EGT, could explain the observed lack of participation. However, when, based on that understanding and by following the principles and findings drawn from EGT, we tried to improve the participation level through remixing of study groups, we did not end up with the expected results: while groups of active participants kept being active, those that were formed of inactive participants remained at low participation levels.

Probing deeper into the issue, we have found that it is not difficult to understand why our remixing method did not work. A close examination of the migration schemes proposed in the EGT literature (e.g., success-driven, aspiration-induced) indicates that individuals move because they want to improve their overall payoff, and every individual has an equal chance of achieving that. In our case, however, active participants were moved to active groups while non-participants were "dumped" into inactive groups. This means we have only helped the active participants in maximising their "payoff" but not the non-participants. The outcome: the active ones continued to be active whereas the inactive ones remained inactive.

In our future studies, we hope to further explore alternative remixing methods, such as spreading active participants across different groups or giving students an option to move across to their preferred group, to see if these could encourage more fruitful collaboration. Or, we could simply allow the remixing procedure to be arbitrary (i.e., random mobility, see Chiong \& Kirley, 2012b; Sicardi, Fort, Vainstein, \& Arenzon, 2009; Vainstein, Silva, \& Arenzon, 2007), giving active participants and non-participants an equal chance to move around. We would also like to investigate the impact of "costs" (the amount of work or effort required to complete a task) and "benefits" (the return students could get from completing the task, e.g., the mark or gained knowledge) on the participation level. This inevitably leads us to issues surrounding the motivation of students: while some students view success in terms of maximising grade while minimising effort, others may be more influenced by the sense of making progress towards mastery (see Gill, 2008). Students with differing motivation hence could affect the behavioural outcome in different ways. The question of task complexity (Gill \& Hicks, 2006) could also be considered, e.g., when group activities are assigned to students, how do they divide things up? The payoff matrices of decom- 
posable tasks (when dividing up is appropriate) and non-decomposable tasks (when dividing up is inappropriate) could be fundamentally dissimilar. Last but not least, drawing inspiration from spatial EGT (Nowak \& May, 1992, 1993) by allowing overlapping groups - a student can be in more than one group - is yet another interesting way to go about.

\section{References}

Aktipis, C.A. (2011). Is cooperation viable in mobile organisms? Simple Walk Away rule favors the evolution of cooperation in groups. Evolution and Human Behavior, 32(4), 263-276.

Axelrod, R. (1984). The evolution of cooperation. New York: Basic Books.

Binmore, K. (2007). Does game theory work? The bargaining challenge. Cambridge, MA: The MIT Press.

Brindley, J.E., Walti, C., \& Blaschke, L.M. (2009). Creating effective collaborative learning groups in an online environment. The International Review of Research in Open and Distance Learning, 10(3), Retrieved from: http://www.irrodl.org/index.php/irrodl/article/view/675/1271

Chiong, R., Dhakal, S., \& Jankovic, L. (2007). Effects of neighbourhood structure on evolution of cooperation in N-player iterated prisoner's dilemma. In Yin, H., Tino, P., Corchado, E., Byrne, W., \& Yao, X. (Eds.), Intelligent Data Engineering and Automated Learning (pp. 950-959). Lecture Notes in Computer Science 4881. Berlin: Springer-Verlag.

Chiong, R., \& Kirley, M. (2009). Co-evolutionary learning in the N-player iterated prisoner's dilemma with a structured environment. In Korb, K., Randall, M., \& Hendtlass, T. (Eds.), Artificial Life: Borrowing from Biology (pp. 32-42). Lecture Notes in Artificial Intelligence 5865. Berlin: Springer-Verlag.

Chiong, R., \& Kirley, M. (2011). Iterated N-player games on small-world networks. In Krasnogor, N., \& Lanzi, P.L. (Eds.), Proceedings of the 2011 Genetic and Evolutionary Computation Conference (pp. 1123-1130). New York: ACM Press.

Chiong, R., \& Kirley, M. (2012a). Effects of iterated interactions in multi-player spatial evolutionary games. IEEE Transactions on Evolutionary Computation, 10.1109/TEVC.2011.2167682

Chiong, R., \& Kirley, M. (2012b). Random mobility and the evolution of cooperation in spatial N-player iterated prisoner's dilemma games. Physica A: Statistical Mechanics and its Application, 10.1016/j.physa.2012.03.010

Cressman, R.. (2003). Evolutionary dynamics and extensive form games. Cambridge, MA: The MIT Press.

Ellis, A. (2001). Student-centred collaborative learning via face-to-face and asynchronous online communication: What's the difference? In Proceedings of the 18th Annual Conference of the Australian Society for Computers in Learning in Tertiary Education (pp. 169-177), Melbourne, Australia.

Finegold, A., \& Cooke, L. (2006). Exploring the attitudes, experiences and dynamics of interaction in online groups. The Internet and Higher Education, 9(3), 201-215.

Gabriel, M. (2004). Learning together: Exploring group interactions online. Journal of Distance Education, 19(1), 54-72.

Garrison, D.R., \& Arbaugh, J.B. (2007). Researching the community of Inquiry Framework: Review, Issues, and Future Directions. The Internet and Higher Education, 10(3), 157-172.

Gaytan, J., \& McEwen, B. (2007). Effective online instructional and assessment strategies. American Journal of Distance Education, 21(3), 117-132.

Gill, T.G. (2008). A psychologically plausible goal-based utility function. Informing Science: the International Journal of an Emerging Transdiscipline, 11, 227-252.

Gill, T.G., \& Hicks, R.C. (2006). Task complexity and informing science: A synthesis. Informing Science: the International Journal of an Emerging Transdiscipline, 9, 1-30.

Gintis, H. (2000). Game theory evolving: A problem-centered introduction to modeling strategic behavior. Princeton, NJ: Princeton University Press. 
Gintis, H., Bowles, S., Boyd, R.T., \& Fehr, E. (Eds.) (2005). Moral sentiments and material interests: The foundations of cooperation in economic life. Cambridge, MA: The MIT Press.

Helbing, D., \& Yu, W. (2008). Migration as a mechanism to promote cooperation. Advances in Complex Systems, 11(4), 641-652.

Helbing, D., \& Yu, W. (2009). The outbreak of cooperation among success-driven individuals under noisy conditions. Proceedings of the National Academy of Sciences of the USA, 106, 3680-3685.

Hofbauer, J., \& Sigmund, K. (1998). Evolutionary games and population dynamics. Cambridge, UK: Cambridge University Press.

Huxham, M., \& Land, R. (2000). Assigning students in group work projects. Can we do better than random? Innovations in Education \& Training International, 37(1), 17-22.

Jiang, L.-L., Wang, W.-X., Lai, Y.-C., \& Wang, B.-H. (2010). Role of adaptive migration in promoting cooperation in spatial games, Physical Review E, 81(3), 036108.

Johnson, D.W., \& Johnson, R.T. (1985). The internal dynamics of cooperative learning groups. In Slavin, R., et al. (Eds.), Learning to Cooperate, Cooperating to Learn (pp. 103-124), New York: Plenum.

Johnson, D.W., \& Johnson, R.T. (1989). Cooperation and competition: Theory and research. Edina, MN: Interaction Book Company.

Johnson, D.W., \& Johnson, R.T. (1990). Cooperative classrooms. In Brubacher, M. (Ed.), Perspectives on Small Group Learning: Theory and Practice, Ontario, Canada: Rubican Publishing Ind.

Jones, C., \& Steeples, C. (2002). Perspectives and issues in networked learning. In Steeples, C., \& Jones, C. (Eds.), Networked Learning: Perspectives and Issues. London: Springer-Verlag.

Juwah, C. (2006). Interactions in online peer learning. In Sharma, R.C., \& Juwah, C. (Eds.), Interactions in Online Education. Implications for Theory and Practice (pp. 171-190). New York: Lawrence Erlbaum.

Kagan, S. (1997). Cooperative learning. San Juan Capistrano, CA: Kagan Cooperative Learning.

Killingback, T., Bieri, J., \& Flatt, T. (2006). Evolution in group-structured populations can resolve the tragedy of the commons. Proceedings of the Royal Society B, 273, 1477-1481.

Killingback, T., \& Doebeli, M. (1996). Spatial evolutionary game theory: Hawks and doves revisited. Proceedings of the Royal Society B, 263, 1135-1144.

Laurillard, D. (2002). Rethinking university teaching: A conversational framework for the effective use of learning technologies, ( $2^{\text {nd }}$ ed.). London: Routledge.

Lin, Y.-T., Yang, H.-X., Wu, Z.-X., \& Wang, B.-H. (2011). Promotion of cooperation by aspirationinduced migration. Physica A: Statistical Mechanics and its Applications, 390, 77-82.

Maynard Smith, J. (1982). Evolution and the theory of games. Cambridge, UK: Cambridge University Press.

Maynard Smith, J., \& Price, G.R. (1973). The logic of animal conflict. Nature, 246, 15-18.

McConnell, D. (2000). Implementing computer supported cooperative learning. London: Kogan Page.

Meister, J.C., \& Willyerd, K. (2010). The 2020 workplace: How innovative companies attract, develop, and keep tomorrow's employees today. New York: HarperCollins Publishers.

Moller, L. (1998). Designing communities of learners for asynchronous distance education. Educational Technology Research and Development, 46(4), 115-122.

Nowak, M.A. (2006a). Evolutionary dynamics: Exploring the equations of life. Cambridge, MA: Harvard University Press.

Nowak, M.A. (2006b). Five rules for the evolution of cooperation. Science, 314, 1560-1563.

Nowak, M.A., \& May, R.M. (1992). Evolutionary games and spatial chaos. Nature, 359, 826-829. 
Nowak, M.A., \& May, R.M. (1993) The spatial dilemmas of evolution. International Journal of Bifurcation and Chaos, 3(1), 35-78.

Nunney, L. (1985). Group selection, altruism, and structured-deme models. The American Naturalist, 126, 212-230.

Oakley, B., Felder, R.M., Brent, R., \& Elhajj, I. (2003). Turning student groups into effective teams. Journal of Student Centered Learning, 2(1), 9-34.

Palloff, R., \& Pratt, K. (2001). Lessons from the cyberspace classroom. San Francisco: John Wiley and Sons.

Panitz, T. (1997). Collaborative versus cooperative learning: Comparing the two definitions helps understand the nature of interactive learning. Cooperative Learning and College Teaching, 8(2). Retrieved from: http://home.capecod.net/ tpanitz/tedsarticles/coopdefinition.htm

Piezon, S., \& Ferree, W. (2008). Perceptions of social loafing in online learning groups: A study of public university and U.S. Naval War College students. The International Review of Research in Open and Distance Learning, 9(2). Retrieved from: http://www.irrodl.org/index.php/irrodl/article/view/484/1034

Rapoport, A., Guyer, M. J., \& Gordon, D. G. (1976). The 2 x 2 game. Ann Arbor, MI: The University of Michigan Press.

Roberts, T.S., \& McInnerney, J.M. (2007). Seven problems of online group learning (and their solutions). Educational Technology \& Society, 10(4), 257-268.

Sanders, M. (2008). A failure to collaborate. The Chronicle of Higher Education, 54(24). Retrieved from: http://wiki-blog-project.wiki.usfca.edu/file/view/A\%2BFailure\%2Bto\%2BCollaborate.PDF

Shaw, S. (2006). New reality: Workplace collaboration is crucial. Eedo Knowledgeware Whitepaper. Retrieved from: http://www.eclo.org/pages/uploads/File/NonECLO\%20Publications/Workplace\%20Collaboration\%20is\%20Crucial.pdf

Sicardi, E.A., Fort, H., Vainstein, M.H., \& Arenzon, J.J. (2009). Random mobility and spatial structure often enhance cooperation. Journal of Theoretical Biology, 256, 240-246.

Siemens, G. (2005). Connectivism: Learning theory for the digital age. International Journal of Instructional Technology and Distance Learning, 2(1). Retrieved from: http://www.itdl.org/Journal/Jan_05/article01.htm

Slavin, R.E. (1983). When does cooperative learning increase achievement? Psychological Bulletin, 94, 429-445.

Smith, G.G., Sorensen, C., Gump, A., Heindel, A.J., Caris, M., \& Martinez, C.D. (2011). Overcoming student resistance to group work: Online versus face-to-face. The Internet and Higher Education, 14(2), 121-128.

Springer, L., Stanne, M.E., \& Donovan, S.S. (1999). Effects of small-group learning on undergraduates in science, mathematics, engineering, and technology: A meta-analysis. Review of Educational Research, 69(1), 21-51.

Stacey, E. (1999). Collaborative learning in an online environment. Journal of Distance Education, 14(2). Retrieved from: http://web.mit.edu/acs/faq/Online-collaboration/collab-learning files/stacey.htm

Stodel, E., Thompson, T., \& MacDonald, C. (2006). Learners' perspectives on what is missing from online learning: Interpretations through the community of inquiry framework. The International Review of Research in Open and Distance Learning, 7(3). Retrieved from: http://www.irrodl.org/index.php/irrodl/article/view/325/743

Tomassini, M. (2008). Games, evolution, and society. Rendiconti Del Seminario Matematico, 66(3), 229258.

Traulsen, A., \& Nowak, M.A. (2006). Evolution of cooperation by multilevel selection. Proceedings of the National Academy of Sciences of the USA, 103, 10952-10955. 
Vainstein, M.H., Silva, A.T.C., \& Arenzon, J.J. (2007). Does mobility decrease cooperation? Journal of Theoretical Biology, 244, 722-728.

Von Neumann, J., \& Morgenstern, O. (1944). Theory of games and economic behavior. Princeton, NJ: Princeton University Press.

Vonderwell, S. (2003). An examination of asynchronous communication experiences and perspectives of students in an online course: A case study. The Internet and Higher Education, 6(1), 77-90.

Vygotsky, L.S. (1978). Mind in society: The development of higher psychological processes. Cambridge, MA: Harvard University Press.

Weibull, J.W. (1995). Evolutionary game theory. Cambridge, MA: The MIT Press.

Wilson, D.S. (1990). Weak altruism, strong group selection. Oikos, 59, 135-140.

Wright, E.R., \& Lawson, A.H. (2005). Computer mediated communication and student learning in large introductory sociology classes. Teaching Sociology, 33(2), 122-135.

Yang, H.-X., Wu, Z.-X., \& Wang, B.-H. (2010). Role of aspiration-induced migration in cooperation. Physical Review E, 81(6), 065101.

\section{Biographies}

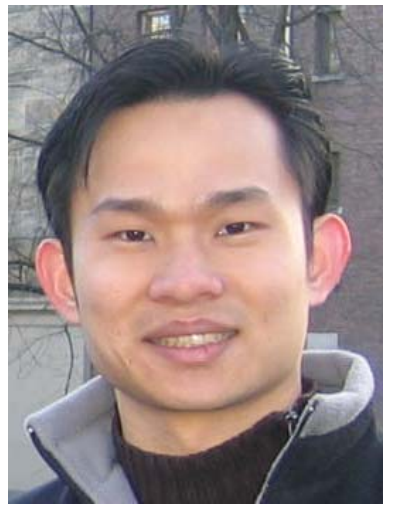

Raymond Chiong is with the Faculty of Higher Education Lilydale, Swinburne University of Technology, Australia. He has been lecturing in Computer Science/Information Systems at both undergraduate and postgraduate levels for many years. His teaching has focused on programming and databases. Besides teaching, he has been actively pursuing research in the areas of evolutionary game theory and optimisation. He is the Editor-in-Chief of the Interdisciplinary Journal of Information, Knowledge, and Management, an Editor of the journal Engineering Applications of Artificial Intelligence, and Guest Editors of a number of special issues in reputable international journals. He is also the Vice Chair of the task force "Education” of IEEE Computational Intelligence Society's Emergent Technology Technical Committee, and one of the Founding Chairs of the IEEE Symposium on Computational Intelligence in Production and Logistics Systems. To date, he has produced over 70 refereed publications. These include 5 books and several papers in top-tier journals.

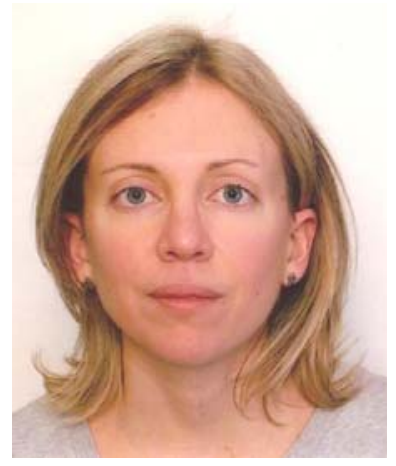

Jelena Jovanovic is with the Faculty of Organizational Sciences, University of Belgrade, Serbia. She has been lecturing in the areas of intelligent systems and software engineering at both undergraduate and postgraduate levels for a number of years now. She is also an active researcher and a practitioner in the fields of intelligent systems and educational technologies. Her primary research interests are in semantic technologies, Web technologies, technology enhanced learning and knowledge management. She is an Editor of the Interdisciplinary Journal of Information, Knowledge, and Management. To date, she has more than 70 refereed publications in books, journals and conference proceedings. 